\title{
Praseodymium-Doped Photo-Luminescent Strontium Indate Nanoparticles by Ultrasonic Spray Pyrolysis
}

\author{
S. E. Lin, K. Borgohain, and W. C. J. Wei ${ }^{\dagger}$ \\ Department of Materials Science \& Engineering, National Taiwan University, Taiwan 106, ROC
}

\begin{abstract}
Submicrometer spherical particles of praseodymium (Pr)-doped strontium indate were synthesized by spray pyrolysis using ultrasonic nebulization. The morphology, crystalline structure, particle size, and size distribution were studied by $\mathrm{X}$-ray diffraction, scanning, and transmission electron microscopies. The spherical agglomerates were found to be made up of very small nanocrystallites. Upon excitation by UV radiation, sharp luminescence emission bands due to $P r$ were observed in the blue, green, and red regions in these Pr-doped samples.
\end{abstract}

\section{Introduction}

$\mathrm{O}$ XIDES doped with rare-earth ions have been extensively studied because of their interesting luminescence properties. ${ }^{1,2}$ The rare earth praseodymium $(\mathrm{Pr})$ is a very attractive activator, because it contains several metastable multiplets, which can lead to a variety of emissions right from the blue to the red and infrared wavelengths,${ }^{3}$ which is of great importance for luminescent devices, especially in modern display technologies like field-emission displays.

Strontium indate $\left(\mathrm{SrIn}_{2} \mathrm{O}_{4}\right)$ has a wide band gap of $3.6 \mathrm{eV},{ }^{4}$ which makes it possible to incorporate luminescent centers of various rare-earth activator ions. To date, studies on indates as a luminescent host material have been very few in number., Rare-earth, Pr-doped indates have the possibility of emitting all the three primary colors of light, which makes it an ideal phosphor for use in modern display panels.

We have used the ultrasonic-assisted spray pyrolysis (SP) technique to obtain submicrometer, spherical, luminescent $\operatorname{SrIn}_{2} \mathrm{O}_{4}$ particles doped with $\mathrm{Pr}$. SP is a simple and rapid process for synthesizing submicrometer, spherical agglomerates. It is commonly used for producing a wide variety of materials in powder form, ${ }^{7}$ e.g., metal oxides, ${ }^{8,9}$ non-oxides, ${ }^{10}$ ceramics, superconducting materials ${ }^{11}$ luminescent materials, ${ }^{12-14}$ and so on. The processing steps involve: (1) generation of small-size (usually in sub- or micrometer size) droplets from the precursor solution or colloidal suspension ${ }^{15,16}$ by nebulization or ultrasonic atomization; (2) carrying the droplet by flow gas, the atomized droplets evaporate when passing through a temperature-controlled furnace; (3) nucleation and crystallization of solid phase on the droplets due to super-saturation of the solution; and (4) densification of the particles during a transient period at a high temperature as desired.

Song et al. ${ }^{8}$ have reported systematic research on controlling the agglomerate size and size distribution by adjusting precursor concentration, gas flow rate, and furnace temperature. How-

J. Ballato-contributing editor

\footnotetext{
Manuscript No. 21616. Received March 22, 2006; approved May 17, 2006.

This work was financially supported by the National Science Council (NSC) in Taiwan, under the contract NSC 93-2120-M-002-011.
}

${ }^{\dagger}$ Author to whom correspondence should be addressed. e-mail: wjwei@ntu.edu.tw ever, to date, no detailed study on the internal structure of the agglomerates has been carried out. We have made an attempt to analyze the nano-scale structure of the particles and study the photo-luminescent (PL) properties of the Pr-doped $\mathrm{SrIn}_{2} \mathrm{O}_{4}$ particles.

\section{Experimental Procedure}

Powder synthesis was carried out by SP using an ultrasonic generator for nebulization of the droplets. $\operatorname{In}\left(\mathrm{NO}_{3}\right)_{3}, \operatorname{Sr}\left(\mathrm{NO}_{3}\right)_{2}$, and $\operatorname{Pr}\left(\mathrm{NO}_{3}\right)_{3}$ solutions were used as the precursors. To study the effect of doping level on the PL properties, samples with three different doping concentrations $(5.0 \%, 0.5 \%, 0.05 \%)$ were prepared and denoted as SP-1, SP-2, and SP-3, respectively. The formulation and experimental conditions for the SP process are listed in Table I.

The powder samples were characterized by X-ray diffraction (XRD; Philips PW 1710 Instrument, Eindhoren, the Netherlands), scanning electron microscopy (FE-SEM, LEO 1530 Instrument, Cambridge, England), and transmission electron microscopy (TEM 100 CXII, JEOL Co., Akishima, Tokyo, Japan). PL measurements were made under ultraviolet excitation $(266 \mathrm{~nm})$ using a frequency-doubled Nd:YAG laser.

For XRD measurements, the sample was dispersed in deionized (DI) water and a film was made on a glass substrate. Samples used for SEM were films deposited directly on Si substrates from SP. The SEM was operated at a voltage of $5 \mathrm{kV}$. For PL measurements, the powder sample was dispersed in DI water and a film was made on an alumina substrate, after which it was calcined at $1000^{\circ} \mathrm{C}$ for $4 \mathrm{~h}$ in a furnace. For TEM observation, samples were prepared by dispersing the particles in $99.5 \%$ pure alcohol and placing a drop of the suspension on a carbon-coated TEM copper grid. In order to study the internal structure of the particles by TEM, a cross section of the particles was prepared. A G1 epoxy (Gatan Coronado, CO) was mixed with the sample powder, taking care so as to obtain a homogeneous mixture of the sample particles and the epoxy. The surface tension of the epoxy mixture forms a thin layer on the TEM copper grid, which was then ion milled (PIPS, Gatan) to obtain a nearly transparent film to electron beam. The operating voltage for TEM was $100 \mathrm{kV}$.

\section{Results and Discussion}

The SEM micrograph of the spherical agglomerates of the asprepared sample SP-2, along with the size distribution obtained by taking into consideration 100 particles from the SEM image, are shown in Fig. 1. The average particle size was about $580 \mathrm{~nm}$.

Figure 2 shows the XRD pattern of the as-prepared sample SP-2. The phase of the particles was found to be predominantly that of $\mathrm{SrIn}_{2} \mathrm{O}_{4}$, which crystallizes in the orthorhombic structure (JCPDS File No. 33-1336), but the $\mathrm{In}_{2} \mathrm{O}_{3}$ phase was also present in a very minor quantity. The XRD patterns for the different doping concentrations were found to be the same. 
Table I. Experimental Conditions for Sample Preparation by Spray Pyrolysis

\begin{tabular}{|c|c|c|c|c|}
\hline \multirow[b]{2}{*}{ Sample } & \multicolumn{2}{|c|}{ Concentration $(\mathrm{mol} / \mathrm{L}) \times 10^{-3}$} & \multirow{2}{*}{$\frac{\text { Doping }(\%)}{\operatorname{Pr}^{3+}}$} & \multirow{2}{*}{$\begin{array}{c}\text { Furnace } \\
\text { temperature }\left({ }^{\circ} \mathrm{C}\right)\end{array}$} \\
\hline & $\operatorname{In}^{3+}$ & $\mathrm{Sr}^{2+}$ & & \\
\hline SP-1 & 16 & 9.6 & 5.0 & 800 \\
\hline SP-2 & 16 & 9.6 & 0.5 & 800 \\
\hline SP-3 & 16 & 9.6 & 0.05 & 800 \\
\hline
\end{tabular}

Note: The concentrations of In and $\mathrm{Sr}$ ions shown are diluted from the original chemicals obtained from Titanex Corp. (Burgstall, Leiblfing, Germany).

Centered dark-field (CDF) TEM images of sample SP-2, as prepared and post-calcined at $800^{\circ} \mathrm{C}$, are shown in Fig. 3. These images reveal that the submicrometer spherical particles are made of small crystallites. The CDF cross-sectional image (Fig. 3(a)) shows that the crystallites are in two size ranges: one is less than $10 \mathrm{~nm}$, and the other ranges from $30 \mathrm{~nm}$ to about $65 \mathrm{~nm}$. The smaller crystallites are $\operatorname{In}_{2} \mathrm{O}_{3}$, whereas the large ones are $\mathrm{SrIn}_{2} \mathrm{O}_{4}$. After calcination at $800^{\circ} \mathrm{C}$ for $4 \mathrm{~h}, \mathrm{In}_{2} \mathrm{O}_{3}$ and $\mathrm{SrIn}_{2} \mathrm{O}_{4}$ crystallites were found to grow to about 17 and $>100 \mathrm{~nm}$, respectively.

The sharp diffraction peaks in the XRD pattern would indicate a larger crystallite size than that obtained from TEM results. The small crystallite size shown by the CDF TEM image is most probably that of $\operatorname{In}_{2} \mathrm{O}_{3}$, while the large ones belong to $\mathrm{SrIn}_{2} \mathrm{O}_{4}$. The crystallite size of $\mathrm{SrIn}_{2} \mathrm{O}_{4}$ being larger than $100 \mathrm{~nm}$ (Fig. 3(b)), the electron beam cannot pass through these large crystallites. Hence, the corresponding electron diffraction pat-
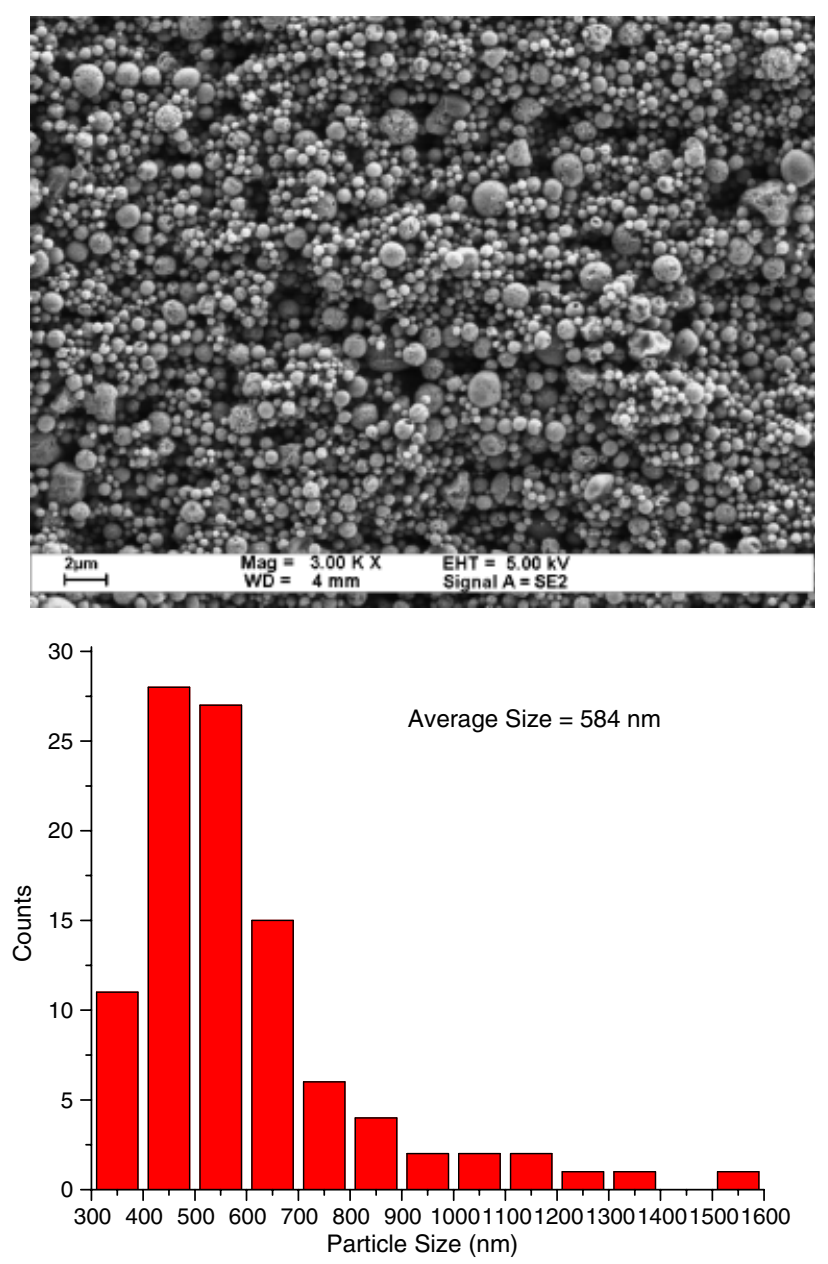

Fig. 1. Scanning electron microscopy micrograph and size distribution histogram of as-prepared sample spray pyrolysis-2.

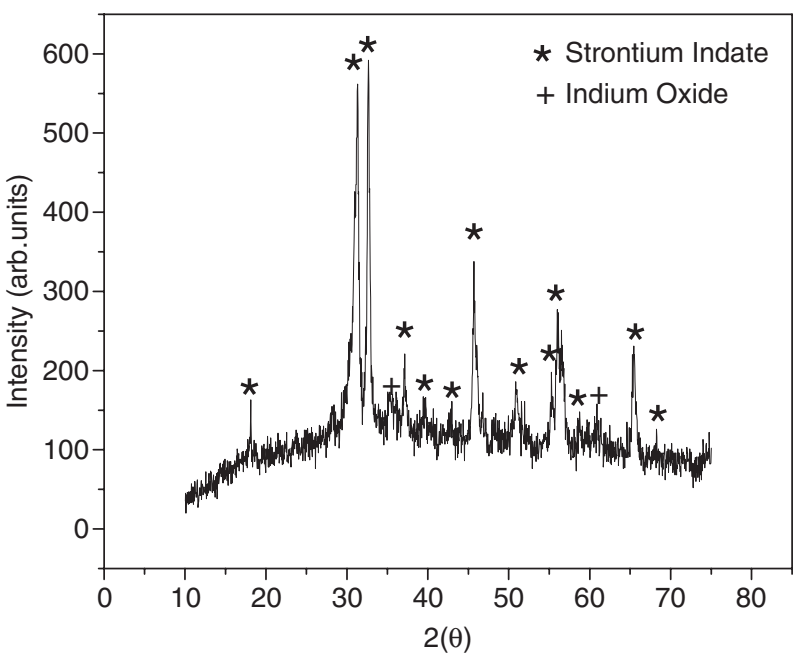

Fig. 2. X-ray diffraction spectra of as-prepared sample spray pyrolysis-2.

tern obtained shows a mixture of $\operatorname{In}_{2} \mathrm{O}_{3}$ and $\mathrm{SrIn}_{2} \mathrm{O}_{4}$. XRD results, on the other hand, mainly show a $\operatorname{SrIn}_{2} \mathrm{O}_{4}$ phase, and very little $\mathrm{In}_{2} \mathrm{O}_{3}$ phase. It can also be seen from XRD results that the diffraction peaks due to $\mathrm{In}_{2} \mathrm{O}_{3}$ are much broader, indicating a smaller crystallite size, whereas that from $\mathrm{SrIn}_{2} \mathrm{O}_{4}$ are very sharp, indicating a larger crystallite size.

For PL measurements, it was noted that the as-prepared, uncalcined samples did not show any PL emission. The samples were therefore post-calcined at $1000^{\circ} \mathrm{C}$ for $4 \mathrm{~h}$, for better PL efficiency. The sample post-calcined at $800^{\circ} \mathrm{C}$ for $4 \mathrm{~h}$ shows PL emission owing to better crystallinity. PL measurements were carried out under ultraviolet excitation $(266 \mathrm{~nm})$ from a frequency-doubled Nd:YAG laser and detected by a PMT. Figure 4 shows the PL spectra of Pr-doped $\mathrm{SrIn}_{2} \mathrm{O}_{4}$ samples with three different doping concentrations $0.05 \%, 0.5 \%$, and $5.0 \%$. The emission spectra show narrow bands typical of rare-earth ions. The most prominent bands were seen in the blue and red region at 492, 605, and $619 \mathrm{~nm}$. Some less intense bands were also seen in the green and red region. The emission features are all due to different transitions from Pr. The blue emission that peaked at $492 \mathrm{~nm}$ is due to transition from ${ }^{3} \mathrm{P}_{0} \rightarrow{ }^{3} \mathrm{H}_{4}$. The 605 emission line is due to the transition ${ }^{1} \mathrm{D}_{2} \rightarrow{ }^{3} \mathrm{H}_{4}$, and the emission at 619 is the ${ }^{3} \mathrm{P}_{0} \rightarrow{ }^{3} \mathrm{H}_{6}$ transition. ${ }^{1}$ Apart from these three main emission bands, the weak band located at $548 \mathrm{~nm}$ is due to the transition ${ }^{3} \mathrm{P}_{0} \rightarrow{ }^{3} \mathrm{H}_{5}$. The emission bands at 654,691 , and $719 \mathrm{~nm}$ can be ascribed to transitions from the ${ }^{3} \mathrm{P}_{0} \rightarrow{ }^{3} \mathrm{~F}_{2,3,4}$ of $\mathrm{Pr}$. It is to be noted that the feature observed at $532 \mathrm{~nm}$ is the second harmonic frequency of the incident laser.

The rare-earth elements have partially filled shells of $f$ electrons that give rise to narrow localized electronic transitions that occur at wavelengths ranging from the far-infrared to the vacuum-ultraviolet. It is also well known that the emission characteristics of rare-earth elements are relatively weakly influenced by the host material. This is because the $4 f$ electrons of the rareearth ions are highly localized due to shielding by the outer filled shells of $5 p$ and $5 s$ electrons, and hence their optical transitions are atomic-like even when the ion is in a crystalline solid. The intensity of PL emission varied with varying concentrations of Pr. The highest PL intensity was observed in the case of SP-2 with a Pr doping of $0.5 \%$. The PL intensity for SP-3 $(0.05 \% \mathrm{Pr})$ was much less and it was the weakest for SP-1 (5\% Pr). The small PL intensity in the case of SP-3 can be explained by the low doping level of Pr, which leads to fewer Pr ions available for emission. In the case of SP-1, the large number of Pr sites could possibly lead to cross-relaxation between the $\mathrm{Pr}$ ions and thus a decrease in the PL intensity. ${ }^{17}$ The parameters for PL measurements for the three samples with different doping concentrations were kept identical so that a comparison of the PL intensities could be made. 


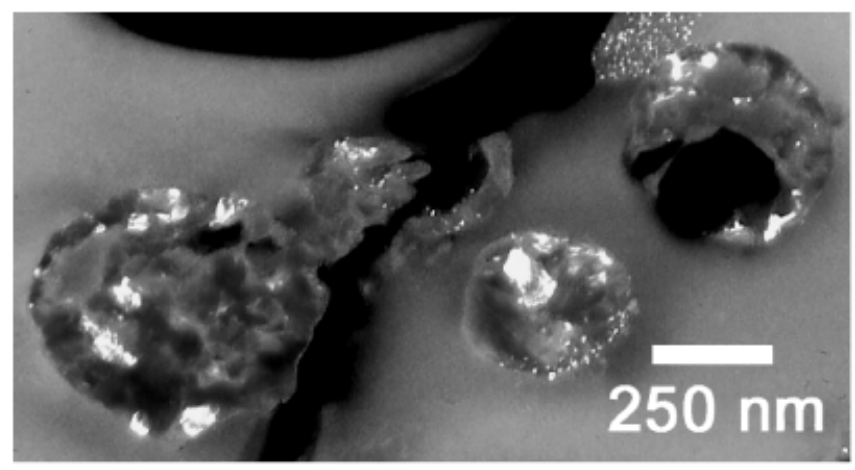

(a)

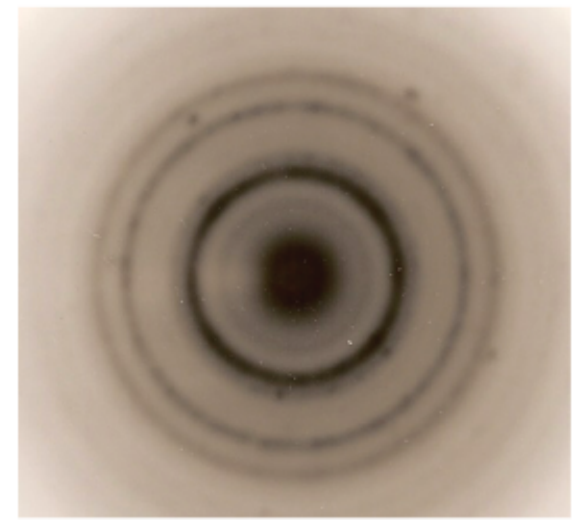

(c)

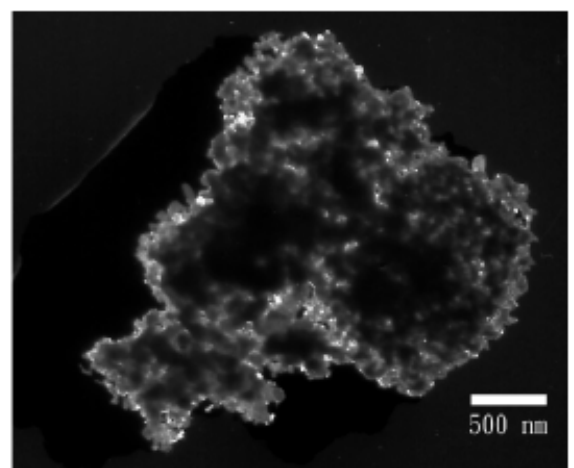

(b)

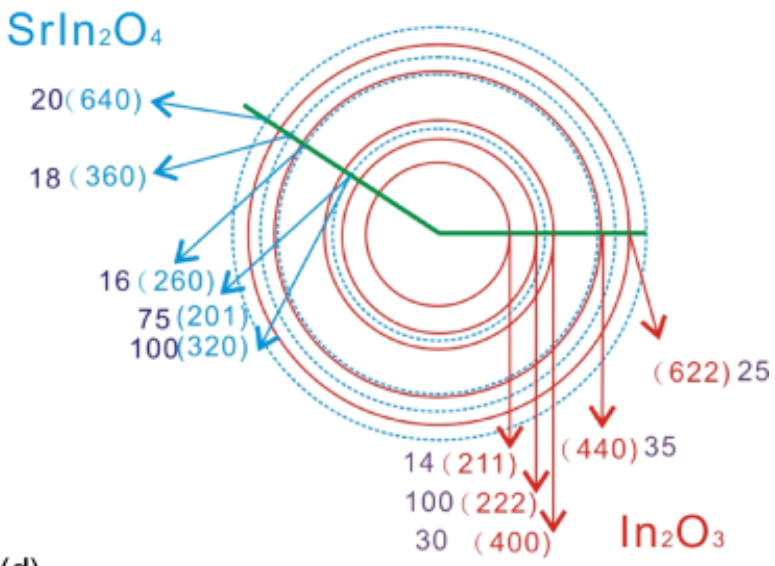

(d)

Fig. 3. Centered dark-field transmission electron microscopy images of sample spray pyrolysis-2 (a) as-prepared in thin section; (b) post-calcined at $800^{\circ} \mathrm{C}$ for $4 \mathrm{~h}$; (c) shows the diffraction pattern of (a); (d) analysis of the diffraction pattern.

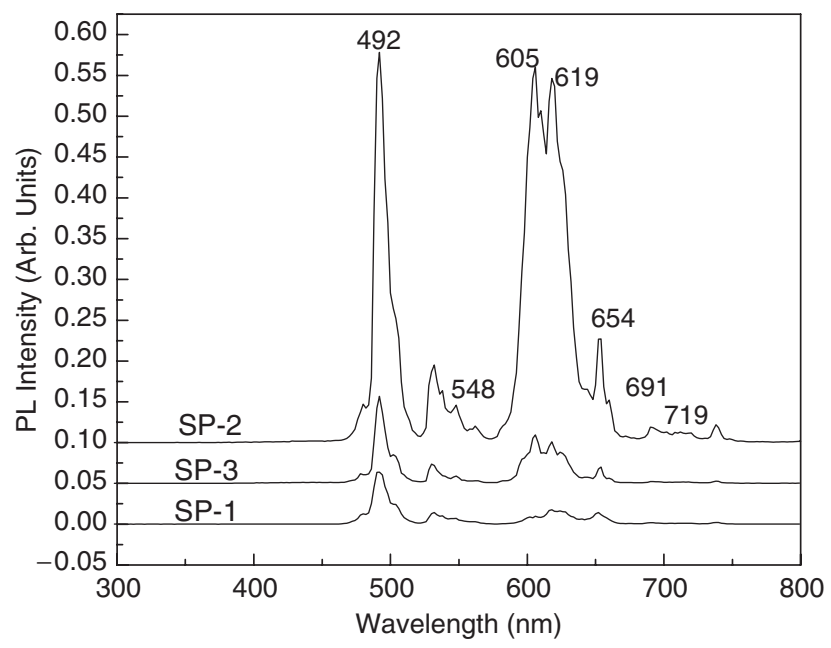

Fig. 4. Photoluminescence spectra of the praseodymium-doped strontium indate samples with varying doping concentrations.

\section{Conclusion}

Spherical, luminescent, Pr-doped $\mathrm{SrIn}_{2} \mathrm{O}_{4}$ particles were obtained by an ultrasonic SP process. SP is a simple and effective technique for obtaining phosphor particles at a low cost. The main advantages of this technique are the high purity, spherical shape, and uniform size character of the powder obtained. XRD and electron diffraction results show that $\mathrm{SrIn}_{2} \mathrm{O}_{4}$ phase is generated at a furnace temperature of about $800^{\circ} \mathrm{C}$. The average powder size as obtained from SEM results was about $580 \mathrm{~nm}$. TEM results show the spherical particles to be polycrystalline, and made up of very small nanocrystallites. CDF TEM images of the agglomerates by TEM show the smallest size of the crystallites to be about $10 \mathrm{~nm}$, which grow to $>100 \mathrm{~nm}$ by calcination at $800^{\circ} \mathrm{C}$. Sharp, blue, green, and red luminescence bands were observed in these Pr-doped $\mathrm{SrIn}_{2} \mathrm{O}_{4}$ samples. The PL intensity varied with varying concentrations of Pr. The highest PL intensity was observed in the case of samples with a Pr doping of $0.5 \%$.

\section{References}

${ }^{1}$ R. Balda, J. Ferna'ndez, I. Sae'z de Oca'riz, M. Voda, A. J. Garcl'a, and N. Khaidukov, "Laser Spectroscopy of $\mathrm{Pr}^{3+}$ Ions in LiKY ${ }_{1-x} \operatorname{Pr}_{x} \mathrm{~F}_{5}$ Single Crystals," Phys. Rev. B, 59, 9972-80 (1999)

${ }^{2}$ M. Malinowski, M. F. Joubert, and B. Jacquier, "Dynamics of the IR-to-Blue Wavelength Upconversion in $\mathrm{Pr}^{3+}$-Doped Ytrium Aluminum Garnet and $\mathrm{LiYF}_{4}$ Crystals," Phys. Rev. B, 50, 12367-74 (1994).

${ }^{3}$ G. H. Dieke, "Chapter 13: Terbium Tb," in Spectra and Energy Levels of Rare Earth Ions in Crystals, Edited by H. M. Crosswhite, and H. Crosswhite. Interscience, New York, 1968.

${ }^{4}$ S. E. Dali, V. V. S. S. Sunder, M. Jayachandra, and M. J. Chockalingan, "Synthesis and Characterization of $\mathrm{Aln}_{2} \mathrm{O}_{4}$ Indates, $\mathrm{A}=\mathrm{Mg}, \mathrm{Ca}, \mathrm{Sr}, \mathrm{Ba}$, " J. Ma ter. Sci. Lett., 17, 619-23 (1998).

${ }^{5}$ F. S. Kao and T. M. Chen, "A Study on the Luminescent Properties of RedEmitting Praseodymium-Activated $\mathrm{SrIn}_{2} \mathrm{O}_{4}$ Phosphors," J.Solid State Chem., 156, 84-7 (2001).

${ }^{6}$ F. S. Kao, "A Study on the Luminescent Properties of New Green-Emitting $\mathrm{SrIn}_{2} \mathrm{O}_{4}: x \mathrm{~Tb}$ Phosphor," Mater. Chem. Phys., 76, 295-8 (2002).

${ }^{7}$ S. Jain, D. J. Skamser, and T. T. Kodas, "Morphology of Single-Component Particles Produced by Spray Pyrolysis," Aerosol Sci. Technol., 27, 575-90 (1997).

${ }^{8}$ Y. L. Song, S. C. Tsai, C. Y. Chen, T. K. Tesng, C. S. Tasi, J. W. Chen, and Y. D. Yao, "Ultrasonic Spray Pyrolysis for Synthesis of Spherical Zirconia Particles," J. Am. Ceram. Soc., 87 [10] 1864-71 (2004).

${ }^{9}$ A. Gurav, T. T. Kodas, T. Pluym, and Y. Xiong, "Aerosol Processing of Materials," Aerosol Sci. Technol., 19, 411-52 (1993).

${ }^{10}$ N. K. Teddy and K. T. R. Reddy, "Growth of Polycrystalline SnS Film by Spray Pyrolysis," Thin Solid Films, 325, 4-6 (1998).

${ }^{11}$ T. T. Kodas, "Generation of Complex Metal Oxide by Aerosol Processes: Superconducting Ceramic Powders and Films," Angew. Chem. Int. Ed. Engl. Adv. Mater., 28 [6] 794-806 (1989). 
${ }^{12}$ Y. C. Kang, H. S. Roh, H. D. Park, and S. B. Park, "Optimization of VUV Characteristics and Morphology of $\mathrm{BaMgAl}_{10} \mathrm{O}_{17}: \mathrm{Eu}^{2+}$ Phosphor Particles in Spray Pyrolysis," Ceram. Int., 29, 41-7 (2003).

${ }^{13}$ S. M. Abrarov, Sh. U. Yuldashev, B. B. Lee, and T. W. Kang, "Suppression of the Green Photoluiminescence Band in $\mathrm{ZnO}$ Embedded into Porous Opal by Spray Pyrolysis," J. Lumin., 109, 25-9 (2004).

${ }^{14}$ Y. C. Kang, H. S. Roh, and S. B. Park, "Preparation of $\mathrm{Y}_{2} \mathrm{O}_{3}$ : Eu Phosphor Particles of Filled Morphology at High Precursor Concentration by Spray Pyrolysis," Adv. Mater., 12 [6] 451-3 (2000).
${ }^{15}$ M. Abdullah, F. Iskandar, S. Shibamoto, T. Ogi, and K. Okuyama, "Preparation of Oxide Particles with Ordered Macropores by Colloidal Templating and Spray Pyrolysis," Acta Mater., 52, 5151-6 (2004).

${ }^{16}$ F. Iskandar, L. Gradon, and K. Okuyama, "Control of the Morphology of Nanostructured Particles Prepared by the Spray Drying of a Nanoparticles Sol," J. Colloid Interface Sci., 265, 296-303 (2003).

${ }^{17}$ J. Hegarty, D. L. Huber, and Y. M. Yen, "Fluorescence Quenching by Cross Relaxation in $\mathrm{LaF}_{3}: \operatorname{Pr}^{3+}$," Phys. Rev. B, 25, 5638-45 (1982). 